\title{
A Peer and Self-assessment Project Implemented in Practical Group Work
}

\author{
Wenjie Qu \\ English Department, Capital University of Economics and Business, Beijing, China \\ Email: quwj@cueb.edu.cn \\ Shuyi Yang \\ English Department, Capital University of Economics and Business, Beijing, China \\ Email: yshuyi2004@yahoo.com.cn
}

\begin{abstract}
Group study which takes students as the central study pattern is of great help for English learners. Nowadays many English teachers select this kind teaching and learning method in the classroom with the aim of enhancing learner's study interest, stimulating their motivation and obtaining the better study result. But actually, the group study simultaneously exists many problems which seriously influence learning effect when it is carrying out in the classroom. However theories and previous researches prove that peer and self-assessment can make students have a clear learning target, discipline themselves and therefore generate better learning results. So peer and self-assessment was put into practical group study in the classroom. Through observing, researching and analyzing of the implementation of it in the classroom, it was found peer and self-assessment could effectively prevent the problems occurring and promoted the group study efficiency greatly.
\end{abstract}

Index Terms - group study, peer and self-assessment, feedback, learning outcome

\section{INTRODUCTION}

In language teaching and learning, two kinds of ability of the use of Language are involved. "One kind is the ability to select which form of sentences is appropriate for a particular linguistic context. The second is the ability to recognize which function is fulfilled by a sentence in a particular communicative situation" (H.G. Widdowson, 1978, p.6).Group work is a good way to make students know how to put English language in a communicative use. A research from Oakland University told us that compared to students taught traditionally, students taught in a manner that incorporate in small-group learning achieve higher grades, learn at a deep level, retain information longer (Oakley, et al., 2004).In terms of speaking, sufficient practice enables students to achieve fluency. Group work can increase the frequency and efficiency of interaction and expression. First and for most, it is conducive to develop student oral communication and problem-solving capabilities. In an easy setting, students have more and better opportunities for freedom to speak. As McCroskey (1984) said students tend to be willing to communicate with others in the target language because of a feeling of comfort, high self-esteem, low anxiety and a desire to take moderate but intelligent risks. Group work provides a communicative environment in which students ultimately have to use the language, productively and receptively, in unrehearsed contexts (Brown, 1980). Group work does provide every team member full opportunities to give play their capability and establish good relations of cooperation. But at the same time group study exists many problems which seriously affect students' learning effect and outcome. The problems are as following: in group study, some students are not centralized when they are in the discussion. They often get off the subject, discussing some contents which have nothing to do with the subject. Some students remove themselves outside the group--study by themselves, or do something else. Some do not listen attentively when their classmates are making presentation, as if it has nothing to do with his or her. In addition, students ignore the chances of learning from each other in group discussion or group presentation. Moreover, individual student's performance and the development are neglected easily by the teacher who is more directed his or her attention on group progress in the process of group learning. Obviously, all of the above problems hinder the smooth development and efficiency of group learning and individual student learning outcome.

However, Peer and self-evaluation assessment is an important way of solving the problems existed in group learning. Peer assessment is an assessment of students by other students, both formative reviews to provide feedback and summative grading (Stephen Bostock, 2000). If something is not assessed it can be seen by students and by staff to be of lesser importance than those aspects of a course which are assessed. Students' attention is therefore focused on those course goals which appear to be assessed over others which are not (David Bound, 1999). Richard G. Sober (2009) stressed self and peer assessment can make students reflect on their own contribution to the team and also voice their opinions on their co-workers and it is essential they have confidence that a sense of fairness will prevail in the marking process. Eddy White (2009) found that peer assessment process did indeed help support and promote student learning about constructing, delivering and judging effective presentations. Luo Shaoqian (2003) suggests assessment is not only 
consistent with the syllabus, but also consistent with the known learning strategies. In peer assessment, students have the opportunity to observe the whole process of learning of their peers, and often the details they observed are more than that of teachers. Peer assessment also promotes autonomous learning, reflective learning and less dependence on the teacher as the supposed expert (Brindley and Scoffield, 1998). It helps students to become more autonomous learners, better able to recognize the strengths and weaknesses of their own work; it enables assessment to become part of the learning process rather than an adjunct to it; Involving students in the assessment process. Andrew Sabaratnam (2006) finds students learn a great deal from each other, and with large student numbers, the importance of student feedback increases as the availability of tutor feedback decreases. Setting up and facilitating student peer-assessment can provide students with deep learning experiences as well as a wealth of feedback to evaluate. Other research concludes students can become better language learners when they engage in deliberate thought about what they are learning and how they are learning it. In this kind of reflection, students step back from the learning process to think about their language learning strategies and their progress as language learners. Such self assessment encourages students to become independent learners and can increase their motivation (Winnie Cheng and Martin Warren, 2000). Allowing students to assess the performance of other group members may therefore provide a more justifiable means of assessment. In a research report from Gu Ying (2006), it shows that partner evaluation methods in the Chinese university classroom in teaching spoken English has a certain validity. Most students hold a supportive attitude of positive evaluation methods; and partner evaluation and teacher evaluation scores are very close. This assessment method can stir up interest in learning, learning motivation and sense of responsibility, to establish a friendly and active benign. In Su Xiuguan's (et al., 2005) action experiment research, she proved that show that students' involvement in developing evaluation criteria and peer assessment promote their studies. She suggested peer assessment should be introduced into the courses and allow students to participate in the making assessment standards in order to benefit student learning and future employment.

From the above statements, we can see peer and self-assessment plays an essential part in our teaching and students' learning process. Through peer and self-evaluation evaluation students can promote mutual supervision among members of the group and learn from each other. It helps stimulate students' motivation.

\section{THE ASSESSMENT RUBRICS DESIGNING}

How to assess student oral English ability is an important aspect of concern. If criteria is too strict and too demanding, it easily leads to students a sense of tension and anxiety and students real standard can't be assessed efficiently; if standard is too low, even without request, it will become a mess and greatly reduce the efficiency of the assessment, all of which will affect the improvement of students learning outcome. In order to mobilize learning enthusiasm of students which is the basic purpose, to improve learner participation, to minimize anxiety, to low self-esteem of students and to strengthen classroom learning process control, the criteria is the key point in assessments.

The assessment rubric for students' practical group learning was made basing Bloom's taxonomy, which helps us determine teaching and assessment of goals. His cognitive objectives in the field include six main categories: knowledge; comprehend; use; analysis; synthesis; evaluation (Nitko, 2007). From low to high ,the Goals not only emphasizes the knowledge, memories and, more importantly emphasize the cultivation of student's intelligence and reflects the cumulative nature of knowledge and level of classification, namely high-level teaching goal is to be achieved through a low-level goals. Bloom's taxonomy is the student behavior is from simple to complex according to the order of arrangement and, therefore, educational objectives are of continuity and cumulative. He focuses on the evaluation of the learning process and looks evaluation as part of the learning process. He advocates teaching should be more use of alternative evaluation methods-formative evaluation. As our students were graduates, they had high cognitive ability, the ability of controlling and the ability of analysis and criticism. Therefore, our main purpose was to assess students' high order thinking--the ability of solving problems by using English and the communication ability in making oral presentation in a real context.

When making particular educational decisions, effective peer evaluation needs a reasonable evaluation principles, they are:

Be clear about the learning targets you want to assess.

Be sure that the assessment techniques you select match each learning target.

Be sure that the selected assessment techniques serve the needs of the learners.

Be sure to use multiple indicators of achievement for each learning target

Be sure that when you interpret the result of assessment you take their limitation into account (Nitko, 2007)

Basing on the above the principles, the peer assessment rubric was made. In order to let students understand and acknowledge the purpose, the importance and the usefulness of the peer and self-assessment, the expectations of them as members participating in group work and how they should contribute towards group work. During the process of making the rubric, students were asked to be involved in the particular assessment decision. Firstly, assessment criteria was presented to students and asked them to give suggestions. Students put forward reasonable some suggestions to the criteria. Then the teacher moderated it according to students' suggestions. Finally evaluation criteria was produced with the involvement of students' work. See Appendix I (Amy Hamilton, 2010) and Appendix II.

The join of discussion of assessment rubrics not only have students to get a clear understanding of the assessment of 
the implementation of standards, operating methods, but also enhance the communication and interaction between teachers and students and promote effective learning and teaching.

\section{THE IMPLEMENTATION AND PEER AND SELF-ASSESSMENT IN PRACTICAL GROUP WORK}

The assessment activity was held twice. The twice assessments activity was anonymous.. 33 students involved in the group and assessment work was divided into 8 groups--4-5 students as a group. All of them were non-English major graduates. For the first time, the assessment was taken within the scale of each group. Each group was given two hours to design and discuss a project of group presentation. The rubric was distributed to each student. See appendix I. After group work, students rated the contribution of each group members and gave comments. The teachers talked with students who were rated low and gave comments in the whole class. The comments were mainly praising and encouraging. Then the peer rating results were feedback to each student. The second time of assessment was held within the scale of the whole class. Each group did a 20-minute presentation with a further 3 minutes for questioning. Each presentation centered around the topic with group members' previous discussion. After each group presentation, student audience had 5 minutes to rate the performance of each group and gave comments, and then to the next round. Each student rated 3 group's performance. The specific requirements were provided to students ahead of two weeks in order to enable students to understand the learning targets and have better learning results. The rubric handout was explained in details in case students made unfair scoring due to ambiguous about the meaning of the rubrics. After all groups' presentation and peer assessment were completed, the evaluation of the results of each group was returned to each group being evaluated to let them get a more comprehensive and evaluation results. Then a face-to-face talk between the teacher and each group members was given and the feedback from the teacher's was provided at the same time. Finally, each student carried out a written self-assessment to enhance a better and complete learning task motivation.

After the peer assessment activity, the teachers had an interview with every group. Students express their opinions of the assessment activity frankly. One said: "I feel it interesting and like it." "I learned a lot from my classmates by rating them." "It makes me excited to be rated and to rate others." There were students spoke frankly:"In the past I usually turned a deaf ear when my classmates were doing presentation. Now I can't. I have to focus my attention on their performance." "Because my classmates were assessing my performance, I forced myself to speak more." a shy student said. One student said: "By reading the comments my classmates gave me, I know I should make my pronunciation clearer and correct afterwards, otherwise the audience do not understand what I'm talking about." Students also said:" Rating is like a mirror which allows us to see our own mistakes and know which mistakes could be avoided." "With the evaluation task, I cannot be distracted. It trains my listening and reminds of myself: Don't make the same mistake as theirs."

After talking with each group students, the teachers' feedback was given to each group both as encouragement and as an instruction for their improvement of future learning. Then each student was asked to make a self-assessment--rating himself and write down their reflections of their performance in the group activities such as advantages, disadvantages and future improvement strategies, and then handed them to the teacher. In their own writing-down assessment, every student made an objective judgment for himself. Some of them said they liked this kind of learning style and hoped other similar English course, such as writing, listening and reading, should adopt it too.

\section{THE ANALYSIS OF IMPLEMENTATION PEER AND SELF-ASSESSMENT IN GROUP WORK}

By implementation of peer and self- assessment in group work students, evaluators and students who were evaluated were all involved in the evaluation process felt the benefits of peer and self-assessment. Peer and self assessment also enhanced the sense of students' responsibility and initiative. D. Sluijsmans (et al., 1998) self-assessment, used in most cases to promote the learning of skills and abilities, leads to more reflection on one's own work, higher quality of products, responsibility for one's own learning, and increasing understanding of problem solving Somervell (1993) found that peer assessment engages students in making judgments about the work or the performance of other students. Students views of peer and self assessment clearly showed that a peer rating did stimulate greater participation and responsibility, establish a clear assessment structure, and improve learning skills and provide more feedback. The performance also proved that students more enthusiastically and actively participated in the group discussion than before. Rare students were found to be distracted away from the group discussion. They performed better in public speaking, they got a good listening habit, and more cooperative. It could be seen from their carefully listening and keep taking notes from the beginning to the end in order to make the assessment well-founded. Implementation peer and self-assessment allowed students both to exchange learning and experience from the performance of fellow students. Self and peer assessment nurture students to learn how to correctly assess their own learning results and learn to be responsible for their own learning. For the evaluators, the adoption of evaluation of others provides a more in-depth look at their own work and found their own inadequacies. It is also the process of promoting evaluators themselves. In the classroom, the process of timely rating and comments made students have timely reflection of their own learning. As Rob East (2008) noted that one of the most obvious benefits of self assessment is that it relates very closely to the aims of personal development planning. This involves students engaging in critical self reflection, focusing on obtaining a clearer idea of the features of effective learning and thereby increasing their understanding of the subject matter being 
studied. Besides, students' assessment provided the teacher valuable information of having a deep understanding of each individual student learning so that the teacher could design a better teaching syllabus and made teaching and learning more targeted and rate students final grades more fair and objective. Because the assessment marks would put into final grades, all the students were extremely carefully and diligent when they were doing group work, assessment and presentation.

Peer and self-assessment is an important component of formative assessment which is often used to set the speed of learning for students to ensure that students to engage in a targeted learning task, to enhance the role of learning, to reveal where the problem lies. It not only changes the previous single interaction between teachers and students, but also greater emphasizes the interaction between peers.

\section{VALIDITY AND RELIABILITY}

Whether the assessment is valid or not, it depends on "how the results are interpreted and used" (Nitko, 2007, p.38). Validity was ensured basically in peer and self-assessment implemented in this practical group work. Because this assessment was implemented based on the requirement of curriculum and was carried out in a real communicative context. Students' ability of solving problems was fully assessed in a real communicative context in which students fully embodied their ability to using English of solving problems and the ability of cooperation etc. The basic purpose of the evaluation was achieved. Another embodiment of validity of peer and self-assessment was it provided a good guide. It inspired the enthusiasm of students learning and very helpful for teachers to design next teaching program. Of course, one time's assessment couldn't determine the actual English proficiency of students. In the future the same assessment should be implemented in classroom teaching at least three times. If the assessment results are consistent, it will be more valid. Reliability is not the assessment instrument itself, it refers to "the consistency of an assessment results if and when they are repeated" (Nitko, 2007, p.57).This assessment has its reliability. Because the evaluation rubric was uniform for all the students who were involved in the assessment. They were from the same profession, the range of their English proficiency differences was the same, and each group assessors was random chosen. All of these avoided the bias in the process of assessment and ensure the results consistent.

\section{CONCLUSION}

As peer and self-assessment is based on student-centered, most students expressed their liking of it. It mobilizes students' enthusiasm, motivates students in their learning, multi-directionally increases their participation in classroom activities, thereby it enhances their oral communicative competence. And as learning is built on the concept of problem-based learning, student cognitive awareness is raised. They are aware of where their strong points are and where their weak points are through peer and self assessment and get to learn how to solve their learning problems. The implementation of peer and self-assessment makes final assessment more rational and convincing, makes teachers better understanding students' learning. Timely, clear and objective feedback provided makes teachers in peer and self-assessment ensure student effective learning and provide encouragement to enhance communication and exchange between teachers and students more powerful learning ability will be reinforced. It also shows that the positive comments from teachers can protect students' self-esteem, self-confidence so as to enhance their learning enthusiasm and initiative.

Potential problems may occur when students doing assessment. For example, some students may rate unfairly because of some personal subjective reasons, but with careful attention, arrangement and implementation, the problems can be avoidable to a great length. Anyhow, the implementation of peer and self assessment really a good way to promote group work efficiency and it is valuable to be popularized in group work.

\section{ACKNOWLEDGEMENT}

We're extremely grateful for the patient and helpful instruction and references provided by Dr. Amy Hamilton and Professor Rosalind Murray-Harvey from Flinders University. Our thanks also go to all the reviewers who gave valuable insights into this paper. Our sincere appreciation also goes to all our students for their support.

\begin{tabular}{|l|} 
APPENDIX I \\
Numerical: eg. rate each criteria out of ten. \\
Graphics: \\
Do the students work well with others? \\
$\qquad \begin{array}{l}\text { Never } \\
\text { Descriptive graphic: as above but with description } \\
\text { Eg. Always works well, shares materials, listen to others opinions, contributes to discussion etc }\end{array}$ \\
\hline
\end{tabular}

(Amy Hamilton, 2010) 


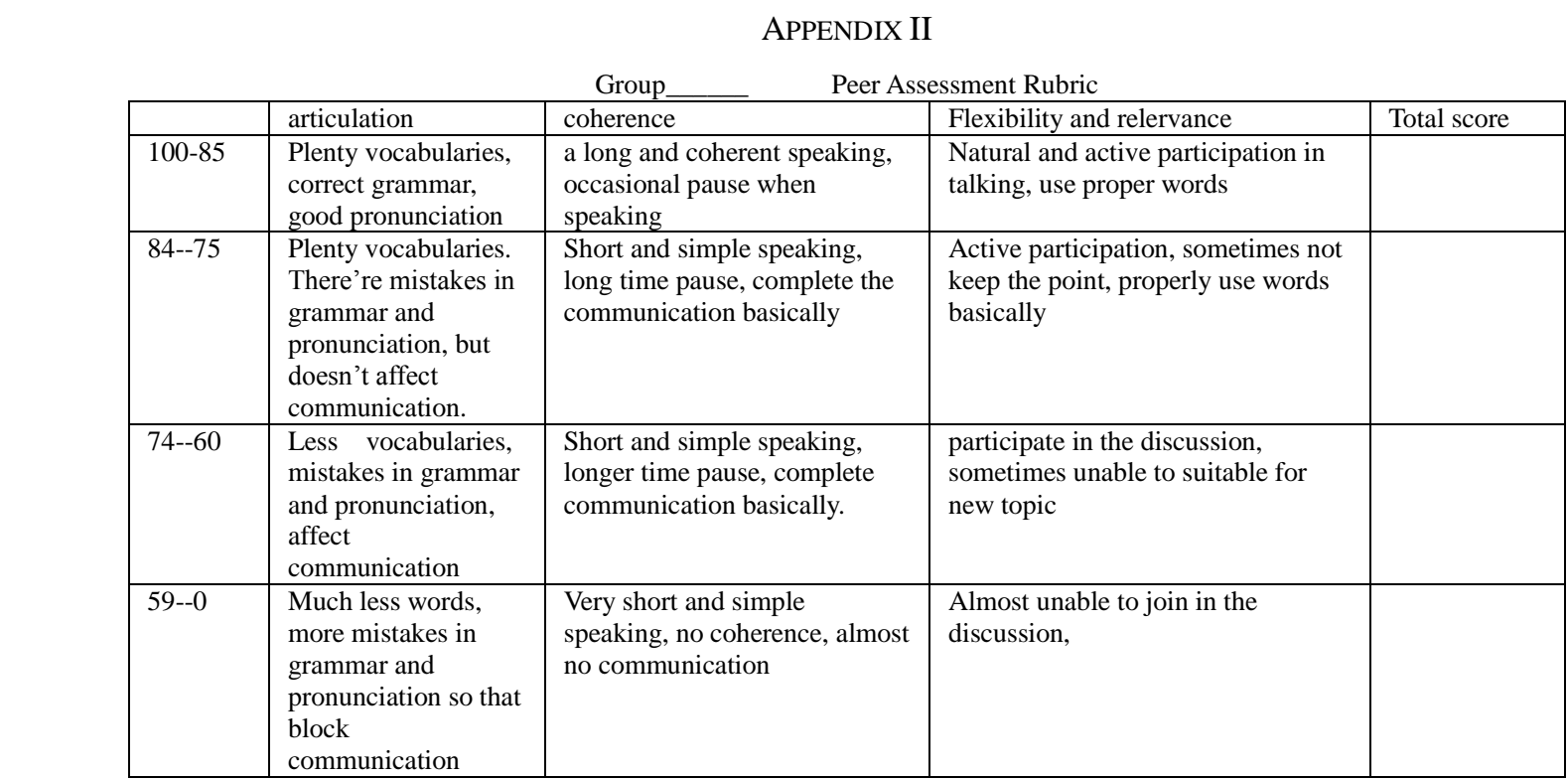

Comments:

\section{REFERENCES}

[1] Amy Hamilton. (2010). Collaborative learning \& self-and peer assessment. EDES9632. Normal Capital University, Beijing.

[2] Anthonyj. Nitko. (2007). Educational Assessment. Upper saddle River, New Jersey Columbus, Ohio.

[3] Andrew Sabaratnam. (2000).Rethinking Assessment and Its Role in Supporting Educational \& Global Reform. Learner's Together. Feb.( assessed 317/2010)

http://www.learnerstogether.net/rethinking-assessment-and-its-role-in-supporting-educational-global-reform/77

[4] Barbara Oakley, Richard M. Felder, Rebecca Brent, Imad Elhajj. (2004).Turning student groups into effective teams. Student Centered Learning Journal, 2(1),9-23,26-27,32-24. New Forum Press. Inc.

[5] Brindley, Clare and Scoffield, Susan. (1998). Peer assessment in undergraduate programs. Teaching in Higher Education. Volume 3, Issue 1, March 1998, pages 79 - 90 (accessed 211212010) http://www.informaworld.com/smpp/992251289-62795666/content $\sim \mathrm{db}=$ all $\sim$ content=a746988322 $\sim \mathrm{tab}=\mathrm{contentstephen}$

[6] Brown, H.D. (1980).Principles of language learning and teaching. Englewood Cliffs, New Jersey: Prentice-Hall, Inc.

[7] David Bound. (1999). Peer Learning and Assessment. Assessment \& Evaluation in Higher Education, Volume 24, Issue 4, pages 413- 426. http://www.informaworld.com/smpp/content $\sim \mathrm{db}=$ all $\sim$ content=a739085288 (accessed 18\2/2010)

[8] D. Sluijsmans, F. Dochy, G. Moerkerke. (1998).Creating a learning environment by using self-peer-and co-assessment. Learning Environment Research. Volume 1, Number3\October http://www.springerlink.com/content/p03342x00v8u7325/ (accessed 2012\2010)

[9] Eddy White. (2009). Student Perspectives of Peer Assessment for Learning in a Public Speaking Course. Professional Teaching Articles. Volume 33. November 2009. http://www.asian-efl-journal.com/pta_Jan_09_ew.php (accessed 201212010)

[10] H. G. Widdowson. (1978). Teaching Language as Communication. London: Oxford University press.

[11] Mc Croskey, J.C. (1984).The communication apprehension perspective. In J.A. Daily \& J.C. McCroskey (eds). Avoiding communication: Shyness, Reticence, and Communicative apprehension pages.13-38.Beverly Hills. CA: Sage.

[12] Richard G. Sober. (2009).Team working and Peer Assessment: The assessment process as an aid to effective learning in creative group project work. The Higher Education Academy (accessed 20\2\2010) http://www.adm.heacademy.ac.uk/resources/case-studies/team-working-and-peer-assessment-the-assessment-

[13] Rob East. (2008). Group, peer and self assessment. The Higher Education Academy http://www.ukcle.ac.uk/resources/assessment/group.html (accessed 17\612010)

[14] Stephen Bostock. (2000). Student peer assessment. The Higher Education Academy http://www.palatine.ac.uk/files/994.pdf (accessed 17\612010)

[15] Somervell, H. (1993). Issues in assessment, enterprise and higher education: the case for self-, peer and collaborative assessment. Assessment and Evaluation in Higher Education, 18, 221-233.

[16] Winnie Cheng, Martin Warren, (2000). Making a Difference: Using Peels to Assess Individual Students' Contributions to a Group Project. Teaching in Higher Education, 1470-1294, Volume 5, Issue 2, 2000, Pages 243 - 255. http://www.informaworld.com/smpp/ftinterface content=a713699111 fulltext=713240930 (accessed 17\6/2010)

[17] Gu Ying. (2006). On the Effectiveness of peer assessment in Oral English Teaching in the effectiveness. Yu Cheng Institute Journal. Yu Cheng Institute Press, China.

[18] Luo Shaoqian. (2003). A study of formative assessment in English classroom. Foreign language teaching and research press. Beijing, China.

[19] Su Xiuguan, Wu Jixia, Fan Xiaohui. (2005). An action research of peer assessment in English teaching. Su Zhou University Journal. Su Zhou University press, China. 
Wenjie Qu, born in April, 1963 got bachelor degree of English major from Normal university of Liao Cheng, China in 1986 and, China and Master degree of pedagogy from Flinders University, Australia in 2010.

She once taught English in Ocean University of China. Now she is teaching English an associate professor of English Department of Capital university of Economics and Business, Beijing, China. Her published three works: (1) Wenjiequ.(2010). A study on summative assessment and formative assessment of English language Teaching. Journal of Capital university of Economics and Business. Volume 68 Capital university of Economics and Business press, Beijing, China. (2) Wenjie Qu (2009). Stimulating foreign language learning motivation--from the perspective of cognition and meta-cognition. US-China Foreign Language. Volume7. David Publishing Company, Illinois, USA . (3) Wenjie Qu (2006).Teaching Assistant's handbook. Beijing Normal university press, Beijing, China. (Translation of the above book).Her research field is applied linguistics and pedagogy.

Shuyi Yang, born on March 18, 1978, graduated from Jilin University as Master of Arts in China in 2002, specializing in English Language and literature.

She is working with the English Department in Capital University of Economics and Business in Beijing China as the Instructor of English. She has translated and published three books and published seven essays. At present she takes great interest in western drama and cross-cultural communication. 